\title{
Creative industrial tourism in Alentejo: The case of the Estremoz Anticlinal Marble Route'
}

\author{
Maria do Rosário Borges ${ }^{1[0000-0003-2519-7535]}$, Noémi Marujo ${ }^{2[0000-0001-8058-5130]}$, Armando \\ Quintas $^{3[0000-0001-8811-6013]}$, Carlos Filipe ${ }^{4[0000-0001-7383-221 X]}$ and Jaime Serra ${ }^{5[0000-0002-0299-}$ \\ 4649] \\ ${ }^{12345}$ CIDEHUS, University of Évora, Largo dos Colegiais, 2; 7000-812 Évora, PORTUGAL \\ mrborges@uevora.pt, noemi@uevora.pt, aquintas.cechap@gmail.com, \\ carlosfilipe2.cechap@gmail.com, jserra@uevora.pt
}

\begin{abstract}
The offer of tourist routes in inland destinations has increasingly assumed a relevant role because they have the potential to give new uses to a great diversity of resources of endogenous character. They have a multifaceted character and are easily adaptable to audiences with very different socio-demographic characteristics in terms of age, educational level, economic level and time availability, among others. This article explores the case of a tourist route that is offered in the segment of creative industrial tourism, in a perspective still under development in the Alentejo region in Portugal. In this approach, creative industrial tourism is understood as the active participation of tourists in educational activities linked to the industrial heritage of a region. Its objective is to characterize the Estremoz Anticlinal Marble Route', in terms of the structure and processes developed for its commercialization. The institutional, socio-cultural and environmental context on which its planning and management was based, coupled with the fact that it was integrated into the CREATOUR network for the enhancement of creative tourism, make this route a reference in the offer of the destination where it operates.
\end{abstract}

Keywords: Industrial Tourism, Creative Tourism, Marble Route.

\section{Introduction}

Despite their being a huge offer of routes around the world, according to Olsen, Trono and Fidgeon "there has been little research on [...] routes and trails within academic literature" [1; p.4]. Also, creative tourism is considered an evolving field [2] and different creative ways of doing tourism should be discussed in the context of theory and practice reflections [3]. This study case contributes to fill in this gap, especially in the field of thematic routes on cultural tourism, with special focus on creative industrial tourism. Tourism routes can be understood as circular or "linear tourist attractions that bring together tourism activities and attractions from different destinations regions that would independently not have the potential to entice visitors to spend time and money" $[1 ; p .2]$. Furthermore, routes are itineraries defined by point of origin, point of destination (which in some cases are coincident) and stops [4] that facilitate visits to different attractions and consumption of specific services. There are different types of routes 